\title{
BIOSORPTION OF REACTIVE DYE BY GRACILARIA VERRUCOSA A MARINE ALGA: BATCH STUDIES
}

\author{
Rajha Amarnath D', T.V.N.padmesh ${ }^{2}$ \\ ${ }^{1}$ Reserch Scholar, ${ }^{2}$ Senior Lecturer \\ Department of Chemical Engineering, Sathyabama University, Jeppiaar Nagar ,Chennai,Tamil Nadu ,India \\ E-mail: tvnpadmesh@yahoo.in
}

\section{ABSTRACT}

The biosorption of Reactive Orange 16 by Gracilaria verrucosa was evaluated under several parameter conditions. The biosorption method consisted of adding $0.2 \mathrm{~g}$ G.verrucosa biomass in $50 \mathrm{ml}$ of dye solution concentrations $(10-1000 \mathrm{mg} / \mathrm{L})$ together in an orbital rotary shaker. The biosorption profile was highly dependent upon the initial $\mathrm{pH}$ concentration, temperature, the adsorbent dosage and size. G.verrucosa biomass exhibited higher uptakes at $\mathrm{pH} 4$ of all concentrations examined. The high uptake values of $0.2 \mathrm{~g} / 50 \mathrm{~mL}$ was observed and then decreased for the further increase in dosage. As the temperature increased the uptake of dye increases up to room temperature and the uptake decreases with further increase in temperature. As the size increased the uptake of dye increased up to $0.5 \mathrm{~mm}$ and the uptake decreases with further increase in size. Therefore size was taken as $0.5 \mathrm{~mm} / 50 \mathrm{~mL}$, for biosorption experiments.Biosorption isotherms have been correctly represented by Langmuir and Freundlich non linear isotherm model. Biosorption isotherm data fitted better into Langmuir model.

KEYWORDS: Reactive dye, De-colorization, Reactive Orange 16, isotherm, Red seaweed, Macroalga

\section{INTRODUCTION}

Combating environmental pollution is a thrust area at this present juncture. In this context, dye effluent of the textile industries has been identified as one of the major pollutant of waterways. Biosorption is a technique that can be used for the removal of pollutants from waters. This technology employs various types of biomass such as dead bacteria, yeast and fungi as source for the decontamination of dye containing effluents. The process basically involves the passive uptake of pollutants from aqueous solutions by the use of non-growing and non -living biomass, that allowing the recovery and/or environmental accepTable- disposal of the pollutants. Recent investigations by various groups have shown that selected species of sea weeds possess impressive adsorption capacities for a range of heavy metal ions but there are few studies on the color removal.

Reactive dyes, the removal of which is examined here, are widely used in many industrial uses due to their bright color, excellent color fastness and ease of application .Reactive dyes are typically azo based chromophores combined with different reactive groups. ${ }^{1}$

In this study, the biosorption of Reactive Orange 16 by Gracilaria Verrucosa was evaluated under several parameter conditions. The initial $\mathrm{pH}$ concentration, the adsorbent dosage, the adsorbent size and the temperature of the dye solution have been investigated. Two equilibrium non linear isotherm models were used to fit the experimental data namely Langmuir and Freundlich models.

\section{MATERIALS AND METHODS}

\section{A. Marine Alga \& Dye}

Gracilaria Verrucosa, was collected from Mandapam and Pulicat, India. It was then sun dried and crushed to particle sizes in the range of 0.1 to $1.0 \mathrm{~mm}$. The crushed particles were then treated with $0.1 \mathrm{M} \mathrm{HCl}$ for $5 \mathrm{~h}$ followed by washing with distilled water and then kept for shaded dry over night. The resultant biomass was subsequently used in sorption experiments. Reactive orange 16 is obtained from Sigma-Aldrich Corporation, Bangalore, India.

\section{RESULTS AND DISCUSSIONS}

\section{A. Batch Experiments}

Batch biosorption experiments were performed in an orbital rotary shaker at $150 \mathrm{rpm}$ using $250 \mathrm{ml}$ Erlenmeyer flasks containing $0.2 \mathrm{~g}$ Gracilaria Verrucosa biomass in 50 $\mathrm{ml}$ of solution containing different reactive dye concentrations. After $12 \mathrm{~h}$, the reaction mixture was centrifuged at $3000 \mathrm{rpm}$ for $10 \mathrm{~min}$. The dye content in the supernatant was determined using UV-Spectrophotometer (Hitachi, Japan) at $494 \mathrm{~nm}$. The amount of dye biosorbed was calculated from the difference between the dye quantity added to the biomass and the dye content of the supernatant using the following equation:

$$
Q=\left(C_{0}-C_{f}\right) * V / M
$$

where $Q$ is the dye uptake $(\mathrm{mg} / \mathrm{g}) ; C_{0}$ and $C_{f}$ are the initial and equilibrium dye concentrations in the solution $(\mathrm{mg} / \mathrm{L})$, respectively; $V$ is the solution volume $(\mathrm{L})$; and $M$ is the mass of biosorbent (g).

\section{Effect of $\mathrm{pH}$}

Dye sorption is highly $\mathrm{pH}$ dependent. Solution $\mathrm{pH}$ is one of the most important environmental factors, which 
influences both the cell surface dye binding sites and the dye chemistry in water. In batch experiments, the effect of initial solution $\mathrm{pH}$ on dye uptake was studied by varying the $\mathrm{pH}$ from 2 to 8 at $10 \mathrm{mg} / \mathrm{L}$ initial dye concentration. The biosorbent dosage and agitation speed (150 rpm) were kept constant. Marine alga biomass exhibited higher uptakes at $\mathrm{pH} 4$ and the results are presented in Fig. 1. The uptake was declined sharply with further increase in $\mathrm{pH}$ upto 6 . The enhancement of uptake of reactive dyes at acidic $\mathrm{pH}$ may be explained in terms of electrostatic attraction between the positively charged surface of the biomass and the dye particles. Reactive dyes are also called anionic dyes because of the negative electrical structure of the chromophore group ${ }^{2}$. As the initial pH increases, the number of negatively charged sites on the biosorbent surface increases and the number of positively charged sites decreases. A negative surface charge does not favour the adsorption of dye anions due to the electrostatic repulsion ${ }^{1}$. A similar trend for binding of reactive and acid dyes by fungus $R$. arrhizus and alga Enteromorpha prolifera has shown maximum values in the range $\mathrm{pH} 2-3$ with a sharp drop off at higher values ${ }^{2,3}$.

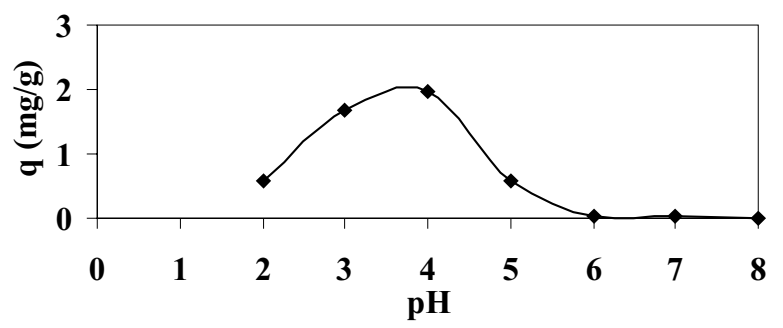

Fig. 1. The effect of initial pH on the equilibrium uptake capacity of Gracilaria Verrucosa of Reactive Orange 16 (temperature $30{ }^{\circ \%} \mathrm{C}$, adsorbent dosage $0.2 \mathrm{~g} / 50 \mathrm{~mL}$, adsorbent size $0.5 \mathrm{~mm} / 50 \mathrm{~mL}$, agitation rate $150 \mathrm{rpm}, \mathrm{Co}=$ $10 \mathrm{mg} / \mathrm{L})$.

\section{Effect of Temperature on dye biosorption}

The effect of temperature also influenced the equilibrium dye uptake. From Fig 2, the temperature range was taken from $25^{\circ} \mathrm{C}$ to $50^{\circ} \mathrm{C}$ at an initial dye concentration of $10 \mathrm{mg} / \mathrm{L}$. It was exhibited that the surface activity decreased with increasing temperatures. As the temperature increased the uptake of dye increases up to room temperature and the uptake decreases further increase in temperature. Therefore room temperature was taken as optimum temperature for biosorption experiments. Further increase in temperature from $30^{\circ} \mathrm{C}$ may alter the surface activity of biomass result in a decrease in removal value, indicating that this process is exothermic in nature. The exothermic nature of dye biosorption has also been reported for the biosorption of Remazol Black B and Acid Red 274 dyes by R. arrhizus and
E. prolifera, respectively ${ }^{3,4}$. The present results showed essentially no thermal deactivation of biosorption activity under operational temperatures.

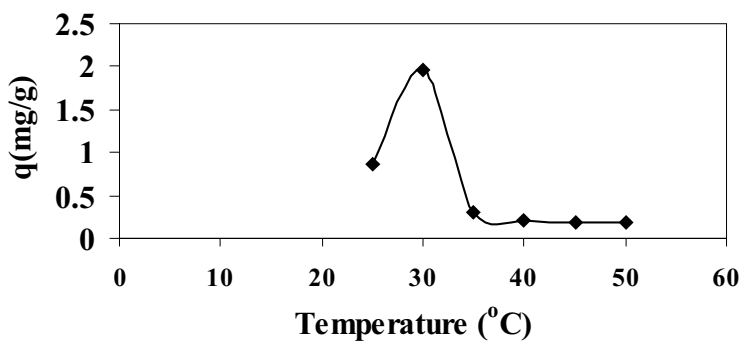

Fig. 2. The effect of temperature on the equilibrium uptake capacity of Gracilaria verrucosa of Reactive Orange $16(\mathrm{pH}$

4.0, adsorbent dosage $0.2 \mathrm{~g} / 50 \mathrm{~mL}$, adsorbent size

$0.5 \mathrm{~mm} / 50 \mathrm{~mL}$,agitation rate $150 \mathrm{rpm}, \mathrm{Co}=10 \mathrm{mg} / \mathrm{L}$ ).

\section{Effect of Biosorbent Dosage}

In batch experiments, the effect of biosorbent dosage on dye uptake was studied by varying the dosage from 0.1 to $0.5 \mathrm{gm}$. For each biosorbent dosage, the dye uptake varied. From Fig 3, marine alga biomass exhibited high uptakes values in low dosage and then decreased for the further increase in dosage. Therefore optimum dosage was taken as $0.2 \mathrm{~g} / 50 \mathrm{~mL}$ for biosorption experiments. The dosage of a biosorbent strongly influences the extent of biosorption. In many instances, lower biosorbent dosages yield higher uptakes and lower percentage removal efficiencies $^{5,6}$.

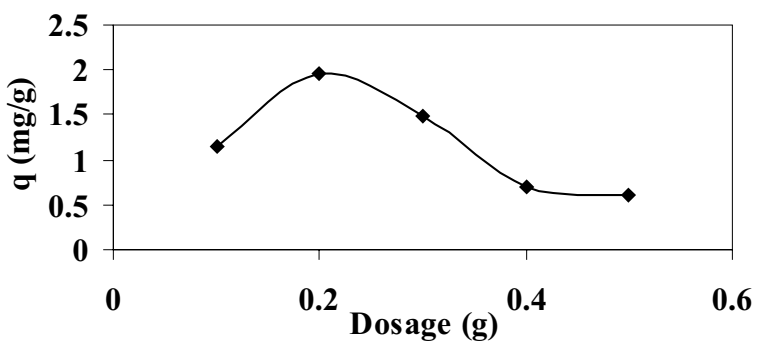

Fig. 3. The effect of dosage on the equilibrium uptake capacity of Gracilaria Verrucosa of Reactive Orange 16

$\left(\mathrm{pH} 4.0\right.$, temperature $30{ }^{\circ \%} \mathrm{C}$, adsorbent size

$0.5 \mathrm{~mm} / 50 \mathrm{~mL}$,agitation rate $150 \mathrm{rpm}, \mathrm{Co}=10 \mathrm{mg} / \mathrm{L}$ ).

An increase in the biomass concentration generally increases the amount of solute biosorbed, due to the increased surface area of the biosorbent, which in turn increases the number of binding sites. Conversely, the quantity of biosorbed solute per unit weight of biosorbent decrease with increasing biosorbent dosage, which may be due to the complex interaction of several factors. An important factor at high sorbent dosages is that the available solute is insufficient to completely cover the available exchangeable sites on the biosorbent, usually resulting in low solute uptake . 


\section{Effect of Biosorbent Size}

The size of the biosorbent also plays a vital role in biosorption. Smaller sized particles have a higher surface area, which in turn favors biosorption and results in a shorter equilibration time. Simultaneously, a particle for biosorption should be sufficiently resilient to withstand the applicable pressures and extreme conditions applied during regeneration cycles ${ }^{7}$. Therefore, preliminary experiments are mandatory to decide the suiTable- size of a biosorbent. The size range was taken from 0.1 to 1.0 $\mathrm{mm} / 50 \mathrm{~mL}$. From Fig 4 , as the size increased the uptake of dye increased up to 0.5 grams and the uptake decreases with further increase in size. Therefore size was taken as $0.5 \mathrm{~g} / 50 \mathrm{~mL}$, for biosorption experiments.

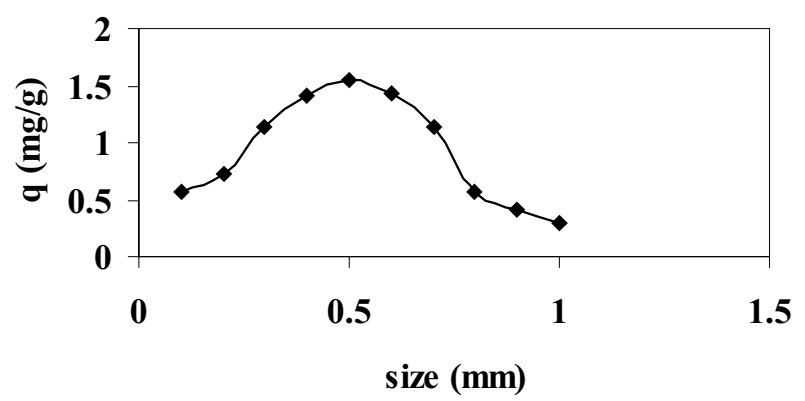

Fig. 4. The effect of size on the equilibrium uptake capacity of Gracilaria Verrucosaof Reactive Orange 16 (initial $\mathrm{pH} 4.0$, temperature $30{ }^{\circ \%} \mathrm{C}$, adsorbent dosage $0.2 \mathrm{~g} / 50 \mathrm{~mL}$, agitation rate $150 \mathrm{rpm}, \mathrm{Co}=10 \mathrm{mg} / \mathrm{L}$ ).

\section{BIOSORPTION ISOTHERM MODELS}

\section{Effect of Adsorption Isotherms}

Isotherm expresses the relation between the mass of dye adsorbed at constant temperature per unit mass of the adsorbent and the liquid phase dye concentration. In the present study, the biosorption capacity and equilibrium isotherm for Reactive Orange onto Marine alga Gracillaria Verucossa were estimated using two equilibrium models: Langmuir and Freundlich isotherm models.

The Langmuir and Freundlich model are the most frequently used two parameter models in the literature describing the non-linear equilibrium between adsorbed pollutant on the cells $\left(q_{\mathrm{e}}\right)$ and pollutant in solution $\left(C_{\mathrm{e}}\right)$ at a constant temperature. The Langmuir equation, which is valid for monolayer sorption onto a homogeneous surface with a finite number of identical sites is given by Eq.

$$
\text { Langmuir: } \quad q=\frac{q_{\max } b C_{f}}{1+b C_{f}}
$$

where $q_{\max }$ is the maximum dye uptake $(\mathrm{mg} / \mathrm{g}), b$ the Langmuir equilibrium constant $(\mathrm{L} / \mathrm{mg})$, relates to bonding energy of adsorption which are functions of the characteristics of the system as well as time ${ }^{8}$.

The Freundlich model is the earliest known relationship describing the sorption equilibrium and is expressed by the following equation

$$
\text { Freundlich: } q=K_{F} C_{f}^{1 / n}
$$

$K_{F}$ the Freundlich constant $(\mathrm{L} / \mathrm{g})$ which corresponds to the binding capacity and $n$ which characterizes the affinity between the sorbent and sorbate, the Freundlich affinity constant. The main reason for the extended use of these isotherms is that they incorporate constants that are easily interpreTable-.

Table 1. Langmuir and Freundlich model parameters at different $\mathrm{pH}$

\begin{tabular}{|l|l|l|l|l|l|l|}
\hline Temp & \multicolumn{3}{|l|}{ Langmuir Parameters } & \multicolumn{2}{l|}{ Freundlich Parameters } \\
\hline${ }^{\circ} \mathbf{C}$ & $\begin{array}{l}\mathbf{q}_{\max } \\
(\mathbf{m g} / \mathbf{g})\end{array}$ & $\begin{array}{l}\mathbf{b} \\
\mathbf{( L / m g )},\end{array}$ & $\mathbf{R}^{\mathbf{}} \boldsymbol{\dagger}$ & $\boldsymbol{K}_{\mathbf{F}}(\mathbf{L} / \mathbf{g})$ & $\mathbf{n}$ & $\mathbf{R}^{\mathbf{}}$ \\
\hline 25 & 134.0889 & 0.004062 & 0.976 & 0.579992 & 1.162984 & 0.8375 \\
\hline 30 & 129.9682 & 0.005744 & 0.981 & 1.074831 & 1.254078 & 0.8706 \\
\hline 35 & 109.9377 & 0.003427 & 0.9827 & 0.766039 & 1.290474 & 0.8904 \\
\hline 40 & 89 & 0.01016 & 0.9772 & 0.717669 & 1.279245 & 0.8699 \\
\hline 45 & 86.53052 & 0.006466 & 0.9788 & 0.641982 & 1.216824 & 0.7878 \\
\hline 50 & 78 & 0.006018 & 0.9627 & 0.777426 & 1.317821 & 0.7636 \\
\hline
\end{tabular}

On increasing the initial dye concentrations, the total dye uptake increased and the total percent removal decreased. For instance, on changing initial Reactive Orange 16 concentrations from 10 to $1000 \mathrm{mg} / \mathrm{L}$, the amount sorbed increased from 1.96 to $100.02 \mathrm{mg} / \mathrm{L}$ at pH 4.But the removal efficiency decreased from 79 to $66.8 \%$ as the Reactive Orange 16 concentration increase from 10 to $1000 \mathrm{mg} / \mathrm{L}$. Langmuir model fitted with the experimental data well, showing correlation coefficient greater than 0.94 for Reactive Orange 16 onto G. Verucossa. $Q_{\text {max }}$ increases with increasing initial $\mathrm{pH}$ and reached maximum at $\mathrm{pH} 4$ .Thus for good biosorbents in general, high $Q_{\max }$ are desirable. The constants evaluated from the isotherms at different $\mathrm{pH}$ with the correlation coefficients are also presented in Table- 1. Fig.4 represents comparison of the experimental and predicted isotherms for Reactive Orange 16 on Gracilaria Verrucossa (initial pH 4.0, temperature 30 ${ }^{8 \%} \mathrm{C}$, biosorbent dosage $0.2 \mathrm{~g} / 50 \mathrm{ml}$, biosorbent size $0.5 \mathrm{~mm} / 50 \mathrm{~mL}$, agitation rate $150 \mathrm{rpm}$ ). The biosorption uptake capacity increase up to room temperature and then decreases by further increasing the temperature. Therefore among the room temperature $\left(30^{\circ} \mathrm{C}\right)$ favoured biosorption. The constants evaluated from the isotherms at 
different temperature with the correlation coefficients are also presented in Table- 2

Table 2. Langmuir and Freundlich model parameters at different Temperature

\begin{tabular}{|l|l|l|l|l|l|l|}
\hline pH & \multicolumn{3}{|l|}{ Langmuir Parameters } & \multicolumn{3}{|l|}{ Freundlich Parameters } \\
\hline & $\begin{array}{l}\mathbf{q}_{\max } \\
(\mathbf{m g} / \mathbf{g})\end{array}$ & $\mathbf{b}$ (L/mg) & $\mathbf{R}^{\mathbf{2}} \boldsymbol{l}$ & $\begin{array}{l}\boldsymbol{K}_{\mathbf{F}} \\
(\mathbf{L} / \mathbf{g})^{1 / n}\end{array}$ & $\mathbf{N}$ & $\mathbf{R}^{\mathbf{}} \mathbf{}$ \\
\hline 2 & 118.9821 & 0.003611 & 0.9637 & 2.422683 & 1.782747 & 0.9004 \\
\hline 3 & 119.9973 & 0.003324 & 0.9686 & 0.687584 & 1.309809 & 0.8665 \\
\hline 4 & 129.9682 & 0.005744 & 0.981 & 1.074831 & 1.254078 & 0.8706 \\
\hline 5 & 115.0085 & 0.002115 & 0.9575 & 0.639579 & 1.330026 & 0.8889 \\
\hline 6 & 113.9821 & 0.004649 & 0.9446 & 1.460166 & 1.485467 & 0.8011 \\
\hline 7 & 109.9762 & 0.003595 & 0.974 & 0.924905 & 1.426792 & 0.8887 \\
\hline 8 & 53.32655 & 0.010027 & 0.9894 & 1.04958 & 1.577273 & 0.8673 \\
\hline
\end{tabular}

\section{Correlation coefficient}

Table 3. Langmuir and Freundlich model parameters at Different dosages

\begin{tabular}{|l|l|l|l|l|l|l|}
\hline Dosage & \multicolumn{3}{|l|}{ Langmuir Parameters } & \multicolumn{3}{l|}{ Freundlich Parameters } \\
\hline $\mathbf{g} /$ & $\begin{array}{l}\mathbf{q}_{\max } \\
\mathbf{5 0} \mathbf{m L}\end{array}$ & $\begin{array}{l}\mathbf{b} \mathbf{m g} / \mathbf{g} \\
(\mathbf{L} / \mathbf{m g}),\end{array}$ & $\mathbf{R}^{2} \boldsymbol{\dagger}$ & $\boldsymbol{K}_{\mathbf{F}}(\mathbf{L} / \mathbf{g})$ & $\mathbf{n}$ & $\mathbf{R}^{2} \mathbf{\dagger}$ \\
\hline 0.1 & 90.10967 & 0.017116 & 0.9549 & 1.150138 & 1.392526 & 0.8058 \\
\hline 0.2 & 129.9682 & 0.005744 & 0.981 & 1.074831 & 1.254078 & 0.8706 \\
\hline 0.3 & 68.45187 & 0.061838 & 0.9493 & 5.821751 & 2.404902 & 0.8231 \\
\hline 0.4 & 26.85852 & 0.044336 & 0.8553 & 18.25071 & 7.493727 & 0.8299 \\
\hline 0.5 & 100.5387 & 0.012489 & 0.8336 & 1.034588 & 1.900918 & 0.8746 \\
\hline
\end{tabular}

Table 4. Langmuir and Freundlich model parameters at different size

\begin{tabular}{|l|l|l|l|l|l|l|}
\hline Size & \multicolumn{3}{|l|}{ Langmuir Parameters } & \multicolumn{3}{l|}{ Freundlich Parameters } \\
\hline $\mathbf{m m} /$ & $q_{\max }$ & & & & & \\
$\mathbf{5 0} \mathbf{m L}$ & $(\mathbf{m g} / \mathbf{g})$ & $\mathbf{b}(\mathbf{L} / \mathbf{m g})$ & $\mathbf{R}^{2} \boldsymbol{\dagger}$ & $\boldsymbol{K}_{\mathbf{F}}(\mathbf{L} / \mathbf{g})$ & $\mathbf{n}$ & $\mathbf{R}^{2} \boldsymbol{~}$ \\
\hline 0.1 & 104.3087 & 0.00854 & 0.9785 & 2.760421 & 1.695341 & 0.8505 \\
\hline 0.2 & 107.8187 & 0.025548 & 0.9128 & 1.611102 & 1.268273 & 0.62 \\
\hline 0.3 & 120.7088 & 0.009302 & 0.9341 & 2.713566 & 1.534594 & 0.7614 \\
\hline 0.4 & 122.0011 & 0.006962 & 0.9855 & 1.701309 & 1.362708 & 0.8628 \\
\hline 0.5 & 129.9682 & 0.005744 & 0.981 & 1.074831 & 1.254078 & 0.8706 \\
\hline 0.6 & 99.02681 & 0.010931 & 0.9855 & 1.191294 & 1.306333 & 0.7808 \\
\hline 0.7 & 92.63062 & 0.004183 & 0.9875 & 0.766156 & 1.290541 & 0.8946 \\
\hline 0.8 & 89.47569 & 0.010076 & 0.9834 & 0.827325 & 1.219592 & 0.7642 \\
\hline 0.9 & 74.34926 & 0.012184 & 0.9405 & 0.799148 & 1.327397 & 0.8034 \\
\hline 1 & 68.87625 & 0.049094 & 0.6827 & 0.144364 & 0.96407 & 0.8155 \\
\hline
\end{tabular}

$? \quad$ EXPT

$? \mathrm{pH}$

$\bigcirc$ SIZE

? TEMP

DOSAGE

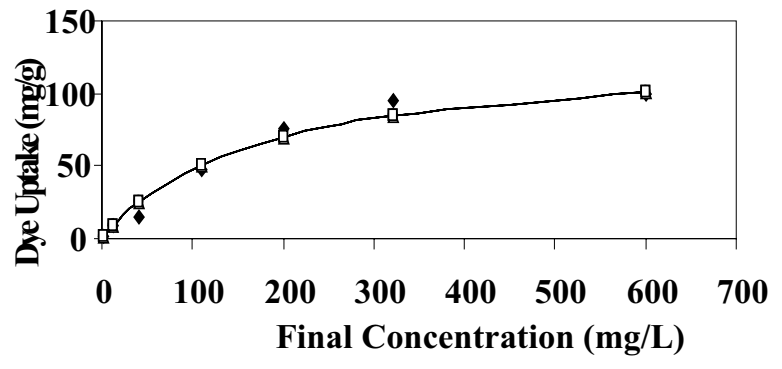

Fig. 5. Comparison of Langmuir non linear model to experimental isotherm data obtained during Reactive Orange 16 biosorption by $\mathrm{G}$. verucossa $(\mathrm{pH} 4.0$, temperature $=30{ }^{\circ \%} \mathrm{C}$, biosorbent dosage $=0.2 \mathrm{~g} / \mathrm{L}$, biosorbent size $=0.5 \mathrm{~mm}$, agitation rate $=150 \mathrm{rpm}$ ).

\section{? EXPT \\ $? \mathrm{pH}$ \\ SIZE \\ ? TEMP \\ $\square$ DOSAGE}

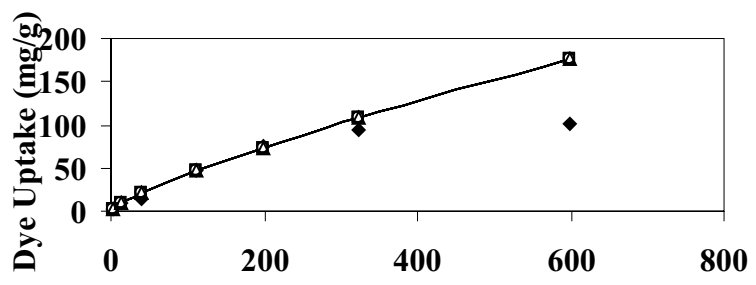

Final Concentration $(\mathrm{mg} / \mathrm{L})$

Fig. 6. Comparison of Langmuir non linear model to experimental isotherm data obtained during Reactive

Orange biosorption by G. verucossa $(\mathrm{pH} 4.0$, temperature $=30{ }^{{ }^{\circ \%} \mathrm{C}}$, biosorbent dosage $=0.2 \mathrm{~g} / \mathrm{L}$, biosorbent size $=0.5 \mathrm{~mm}$, agitation rate $=150 \mathrm{rpm}$ ).

As represented in fig. Fig.5 the Langmuir model exhibited slightly better fit to the biosorption data for the dye than Freundlich models in the studied concentration and temperature ranges. The maximum capacity $Q_{\max }$ determined from the Langmuir isotherm defines the total capacity of the biosorbent for Reactive Orange as 129.96 $\mathrm{mg} / \mathrm{g}$ at $30^{\circ} \mathrm{C}$. The maximum adsorption capacity of biomass deceased with further increasing temperature. From the Fig 3 , the biosorption uptake capacity increase up to $0.2 \mathrm{gms}$ and then decreases by further increasing the dosage. Therefore among the dosages $0.2 \mathrm{~g}$ favoured biosorption. The constants evaluated from the isotherms at different dosages with the correlation coefficients are also presented in Table- 3

From Fig.6.the Langmuir model exhibited slightly better fit to the biosorption data for the dye than Freundlich model in the studied concentration and dosage ranges. The maximum capacity $Q_{\max }$ determine from the Langmuir 
isotherm defines the total capacity of the biosorbent for Reactive Orange as $129.96 \mathrm{mg} / \mathrm{g}$ at $0.2 \mathrm{~g}$.

\section{SUMMARY AND CONCLUSIONS}

The results from this research show that the biosorption is a viable process for the removal of textile reactive dyes from aqueous solutions. In this study, the biosorption examined superior biosorption uptake in batch operations. Since this seaweed (Gracillaria Verucossa) is readily available in the environment; it is more economical and can yield sorbet of higher sorption capacity Further study focused on the industrial waste water is needed. The experimental data was fitted with nonlinear isotherm models such as Langmuir and Freundlich, in batch mode of experiments. Langmuir sorption model served to estimate the maximum uptake values, where they could not be reached in the experiments and have high correlation coefficients..

\section{REFERENCES}

[1] Namasivayam C, Kavitha D, Removal of Congo Red from water by adsorption onto activated carbon prepared from coir pith, an agricultural solid waste, Dyes Pigments (54) ,47, 2002.

[2] OÜMahonyT, Guibal E, Tobin JM. Reactive dye biosorption by Rhizopus arrhizus biomass. Enzyme Microb Technol;(31),456, 2002.

[3] Ozer, A., Akkaya, G., Turabik, M.,. Biosorption of acid red 274 (AR 274) on Enteromorpha prolifera in a batch system. J. Hazard. Mater. B126, 119, 2005.
[4] Aksu Z, SS. Investigation of biosorption of Gemazol Turquise Blue-G reactive dye by dried Rhizopus arrhizus in batch and continuous systems. Sep Purif Technol; 48:24, 2006.

[5] Vijayaraghavan K, Palanivelu K, Velan M. Biosorption of copper (II) and cobalt (II) from aqueous solutions by crab shell particles. Biores Technol; 97: 1411, 2006.

[6] Esposito A, Pagnanelli F, Lodi A, Solisio C, V F. Biosorption of heavy metals by Sphaerotilus natans: an equilibrium study at different $\mathrm{pH}$ and biomass concentrations. Hydrometallurgy; 60:129, 2001.

[7] Volesky B. Detoxification of metal-bearing effluents: biosorption for the next century. Hydrometallurgy; 59:203, 2001.

[8] Langmuir I. The adsorption of gases on plane surfaces of glass, mica and platinum. J Am Chem Soc; 40:1361, 1918.

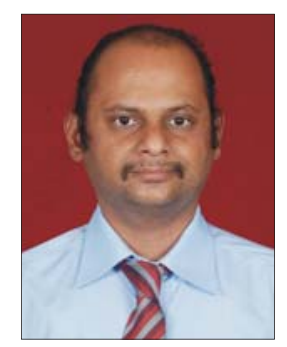

Mr. Rajha Amarnath.D is a Chemical Engineer with Petroleum Refining and Petrochemicals as specialization at Post Graduate level. He has 14 years of teaching experience and now working as Assistant Professor in Sathyabama University in the Department of Chemical Engineering. 